Allison Langham-Putrow and Emily Ford

\title{
A call for submissions
}

\section{Share your thoughts in the Scholarly Communication column}

Many readers may not know that this column is edited by members of ACRL's Research and Scholarly Environment Committee. Taking this on has been invigorating and refreshing for us and feels like a concrete way to contribute to ACRL every month. Probably much like you, dear readers, we are librarians working in academic environments that are shortstaffed, underfunded, and have been attempting to approach our duties and tasks in new ways because of the pandemic. We're also continuing to solicit, edit, and publish thoughtful, timely, and interesting content in this column.

Scholarly communication is ever changing and that is what keeps so many of us so interested in it. As such, we hope that you will contribute your thoughts to the column, in light of the changes you've been noticing and the thoughts that you have been having. If you'd like to submit an article or propose an idea to this column, we invite you to do so. Tell us what has been on your mind. Here's what has been on ours.

\section{Reflections on practice}

Scholarly communication work continues to evolve, and librarians work on an enormous range of issues. How has the environment changed? What trends do you see persisting? What actions are needed now? Perhaps you are a librarian who works in scholarly communication and are (mentally) moving to a new stage of your career. How has your work or have your views changed as you move from early career to mid-career? (It's up to you to decide whether you are early, mid, or late career.)

\section{Article processing charges}

Many publishers use an open access model that requires payment of a per article processing charge (APC) from the author or their institution. Some libraries have a dedicated fund for helping authors pay these charges, but often the fund is small and rarely can a library afford to pay for all charges incurred by their authors. Does or did your library have a fund? What prompted its creation or closure?

Thinking more broadly, how do APCs affect the diversity and inclusion of all voices in the scholarly conversation? Have you encountered APCs in your own scholarly output? Could you afford your ideal journal's APC? How many of your paychecks would you need

Allison Langham-Putrow is scholarly communications and engineering liaison librarian, research services coordinator at the University of Minnesota, email: lang0636@umn.edu, and Emily Ford is urban and public affairs librarian at Portland State University, email: forder@pdx.edu 
to use to pay the APC out of pocket? Do you have experience navigating the APC waiver system from your own work or through supporting a researcher at your institution? Are APCs even ethical?

\section{Transformative agreements and equity, diversity, and inclusion}

Transformative agreements are intended to move the scholarly publishing system from one in which institutions pay to provide access to materials (i.e., subscriptions) to one in which institutions pay for their authors to publish their work openly (either eliminating the payment from the author or providing a discount). They are beneficial to authors who work at institutions that can afford agreements, but what does this shift mean for authors who are unaffiliated with an institution or are at an institution that cannot afford, or do not agree with the ethics of, these agreements? Will "transforming the system" from pay-to-read to pay-to-publish lead to a more equitable or less equitable environment? Do these agreements change the system or are they reinforcing the publishing oligopoly?

\section{"Predatory" publishers}

In a recent article, D. Mills and K. Inouye reviewed literature on "predatory publishing." Twelve of the sixteen articles they explore in depth use a list of predatory journals and publishers created by one (white man) and based on ill-defined criteria. This list is also commonly referred to in discussions on library listservs and at librarian-led conferences. Why are we still using this list? What does it say about us as a profession if we continue to categorize journals or publishers into a "predatory" and "not predatory" dichotomy? How do you discuss the concept of "predatory publishing" with authors on your campus?

\section{Other ways of knowing in scholarly communication}

Scholarly communication, at its core, is a practice steeped in the culture of the dominant academic class. There are many other ways that people know things. ${ }^{2}$ For example, Native Americans and other indigenous peoples have traditional cultural expressions_- knowledge that is passed down generationally and knowledge that may not be ethical to share outside of these communities. Knowledge, in Western academic culture, is written, and therefore knowledge becomes codified. Indeed, "The call for rigour is also often the call for the elimination of difference." 3 How can scholarly communication practices bridge beyond this tradition? How can we make space for other ways of knowing in scholarly communication practices? How might we offer reparations for the misuse of nonwhite ways of knowing, in light of what Miranda H. Belarde-Lewis and Sarah R. Kostelecky describe in their chapter "Tribal Critical Race Theory in Zuni Pueblo"? "Research by outsiders has resulted in the publication and dissemination of ancient sacred knowledge, esoteric traditions, and religious practices—without free, prior, and informed consent of the Zunis." ${ }^{4}$

\section{Communicating with your campus}

Many of our libraries are facing challenges given the pandemic, economic downturns, and the effects of the COVID-19 pandemic. Have these challenges changed the way you communicate with your campus? Have you had successes (or failures-we can all learn from these)? Is your library facing budget cuts? If you have unbundled a publisher package, how 
have you communicated these changes with your campus? Publishers are more often approaching libraries with offers for transformative agreements that combine subscription access with an open access publishing component. Is your library considering one of these, and, if so, does this agree or conflict with work, like unbundling, that you might have been doing to manage subscription prices?

There have also been reports of publishers circumventing the library, approaching university administration or faculty to apply pressure to enter into (typically very expensive) agreements. Have you experienced this? How did you navigate the complex relationships on campus?

\section{Open Science advancements}

In November 2021, UNESCO adopted its Recommendations on Open Science. ${ }^{5}$ Similarly, the National Academies of Science, Engineering, and Medicine have been actively working to promote and develop open science practices and frameworks. ${ }^{6}$ What is the role of libraries in supporting open science? Have you created any programs to support researchers on your campus in making all parts of their work open - not just publications, but data, code, and other research materials?

\section{Open Educational Resources}

What is the intersection between open educational resources (OER) and scholarly communication? Are they one in the same? Are OER inherently scholarly communication? With so many library resources being put behind the creation and publishing of OER, how will we balance other scholarly communication work?

\section{Technical solutions and innovations}

What can new technologies, apps, implementations, or standards contribute to scholarly communication. For example, have you used hypothes.is to markup documents for peer review? Does your library publishing program struggle with providing XML, JATS, or meeting other technical requirements for publications ${ }^{7}$ (e.g., to comply with Plan S, which, although primarily a European program, can affect scholars who collaborate internationally)? What do you think of artificial intelligence and its role in the scholarly communication of the future? (Is scholarly communication work going to be taken over by robot overlords? If so, is that a good thing or a bad thing?)

\section{Anti-racist practices and critical takes on accepted practices}

In a recent book chapter, Harrison Inefuku shares four gatekeeping processes impacting scholarly communication. "Through these processes, academic publishing in the United States creates a body of knowledge that privileges a white worldview and marginalizes the perspectives, experiences, and contributions of communities of color." ${ }^{8}$ How can we break these processes? How can we reinvent them? One example might be to put the anti-racist scholarly reviewing practices into place. ${ }^{9}$ Have you implemented these practices in your own research and publishing, with journals published by your library in your library's promotion requirements? How has it worked? What have you learned? Is there something that is an accepted "norm" in scholarly communication that shouldn't be? Do you have a 
\#critlib or \#crt lens of how we write, distribute, pay for, and otherwise support scholarly communication as librarians?

\section{Call for submissions}

While these are topics we have been thinking about, you may have been mulling over something else. We want to hear from you on these and other topics. Reach out to us at crlnscholcomm@gmail.com. Send us an outline or a short description. If you're not sure about how to scope your contribution, we would be happy to work with you.

\section{Notes}

1. D. Mills and K. Inouye, "Problematizing 'Predatory Publishing': A Systematic Review of Factors Shaping Publishing Motives, Decisions, and Experiences," Learned Publishing 34, no. 2 (April 2021): 89-104, https://doi.org/10.1002/leap.1325.

2. Paul Wildman and Sohail Inayatullah, "Ways of Knowing, Culture, Communication and the Pedagogies of the Future," Futures 28, no. 8 (October 1996): 723-40, https://doi. org/10.1016/0016-3287(96)00031-6.

3. Wildman and Inayatullah, 733-734.

4. Miranda H. Belarde-Lewis and Sarah R. Kostelecky, "Tribal Critical Race Theory in Zuni Pueblo: Information Access in a Cautious Community," in Knowledge Justice: Disrupting Library and Information Studies through Critical Race Theory by Sofia Y. Leung, Jorge R. López-McKnight, p. 111, https://doi.org/10.7551/mitpress/11969.003.0008.

5. UNESCO, "UNESCO Recommendation on Open Science," 2021, https://unesdoc. unesco.org/ark:/48223/pf0000379949.locale=en.

6. National Academies of Sciences, Engineering, and Medicine (U.S.), ed., Open Science by Design: Realizing a Vision for 21st Century Research, A Consensus Study Report (Washington, DC: The National Academies Press, 2018), National Academies of Sciences, Engineering, and Medicine, "Roundtable on Aligning Incentives for Open Science," December 13, 2021, https://www.nationalacademies.org/our-work/roundtable-on-aligning -incentives-for-open-science.

7. Principles and Implementation, Part III: Technical Guidance and Requirements, https://www.coalition-s.org/addendum-to-the-coalition-s-guidance-on-the-implementation -of-plan-s/principles-and-implementation/.

8. Harrison W. Inefuku, "Relegated to the Margins: Faculty of Color, the Scholarly Record, and the Necessity of Antiracist Library Disruptions," in Knowledge Justice: Disrupting Library and Information Studies through Critical Race Theory by Sofia Y. Leung, Jorge R. López-McKnight, p. 198.

9. "Anti-Racist Scholarly Reviewing Practices: A Heuristic for Editors, Reviewers, and Authors," 2021, https://doi.org/ 10.7551/mitpress/11969.003.0014. „ 